\title{
Analyzing the minor volatilome of Torulaspora delbrueckii in an alcoholic fermentation
}

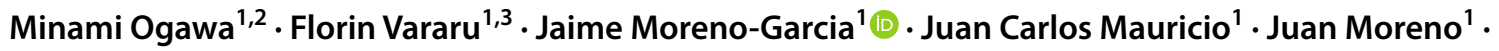 \\ Teresa Garcia-Martinez ${ }^{1}$
}

Received: 15 February 2021 / Revised: 2 November 2021 / Accepted: 7 November 2021 / Published online: 30 November 2021

(c) The Author(s) 2021

\begin{abstract}
Torulaspora delbrueckii is an emerging yeast species in the beverage and food industry that is suitable for alcoholic fermentation and to improve the organoleptic quality of wine, beer, mead, and other beverages. Modern consumer preference toward new flavors and products drives the application of $T$. delbrueckii to ferment less traditional fruits and vegetables. Thus, it has become increasingly relevant to define those metabolites produced in minute quantities by $T$. delbrueckii, because they may have an impact when producing these new alcoholic beverages. In this study, we have identified metabolites of $T$. delbrueckii and have compared them with those of Saccharomyces cerevisiae in a controlled setting with a synthetic, high glucose medium using gas chromatography coupled to flame ionization detector (GC-FID) and stir bar sorptive extraction (SBSE) with GC coupled to mass spectrometry (MS). Results showed that T. delbrueckii produced metabolites with higher changes in odor activity complexes than $S$. cerevisiae: ethyl propanoate, 1,1-diethoxyethane, ethyl isobutyrate, ethyl butyrate, isoamyl acetate, ethyl heptanoate, nonanal, and decanal. We also report seven metabolites detected for the first time in $T$. delbrueckii. This datum serves to expand the knowledge of $T$. delbrueckii performance and shows that application of this yeast species is more suitable to a wide array of beverage producers.
\end{abstract}

Keywords Torulaspora delbrueckii $\cdot$ Saccharomyces cerevisiae $\cdot$ Metabolites $\cdot$ Volatile compounds $\cdot$ Fermentation

\begin{tabular}{|c|c|c|c|}
\hline & & Abbreviations & \\
\hline & & ANOVA & Analysis of variance \\
\hline$\square$ & $\begin{array}{l}\text { Jaime Moreno-Garcia } \\
\text { b62mogaj@uco.es }\end{array}$ & $\begin{array}{l}\text { EI } \\
\text { GC-FID }\end{array}$ & $\begin{array}{l}\text { Electron impact } \\
\text { Gas Chromatography-Flame Ioni- } \\
\text { zation Detector }\end{array}$ \\
\hline & $\begin{array}{l}\text { Minami Ogawa } \\
\text { amigawa@ucdavis.edu }\end{array}$ & $\mathrm{GC} / \mathrm{MS}$ & $\begin{array}{l}\text { Gas Chromatography-Mass } \\
\text { Spectrometry }\end{array}$ \\
\hline & Florin Vararu & HG & Homogenous groups \\
\hline & florinvararu@yahoo.com & LRI & Linear retention indices \\
\hline & Juan Carlos Mauricio & OAV & Odor Activity Value \\
\hline & mi1gamaj@uco.es & OIV & International Organisation of Vine \\
\hline & Juan Moreno & & and Wine \\
\hline & qe1movij@uco.es & PCA & Principle Component Analysis \\
\hline & Teresa Garcia-Martinez & PDMS & Polydimethylsiloxane \\
\hline & mi2gamam@uco.es & SBSE-TD-GC-MS & Stir Bar Sorptive Extraction-Ther- \\
\hline 1 & $\begin{array}{l}\text { Department of Agricultural Chemistry, Edaphology } \\
\text { and Microbiology, Agrifood Campus of International }\end{array}$ & & $\begin{array}{l}\text { mal Desorption-Gas Chromatogra- } \\
\text { phy-Mass Spectrometry }\end{array}$ \\
\hline & Excellence ceiA3, University of Córdoba, Córdoba, Spain & YPD & Yeast extract Peptone Dextrose \\
\hline 2 & Department of Food Science and Technology, University & YAN & Yeast Assimilable Nitrogen \\
\hline & $\begin{array}{l}\text { of California, } 392 \text { Old Davis Rd, DavisDavis, CA 95616, } \\
\text { USA }\end{array}$ & YNB & Yeast Nitrogen Base \\
\hline 3 & $\begin{array}{l}\text { University of Agricultural Sciences and Veterinary Medicine, } \\
\text { Mihail Sadoveanu Alley, } 700490 \text { Iasi, Romania }\end{array}$ & & \\
\hline
\end{tabular}




\section{Introduction}

Non-Saccharomyces yeast species have gained steady interest in the production of alcoholic beverages due to their contributions of increasing aromatic complexity and improving organoleptic properties. Naturally found on the skins of fruits, these indigenous yeasts refer to those species that have positive roles in beverage production, excluding S. cerevisiae [1]. Although non-Saccharomyces were once considered spoilage organisms, this belief has now changed and considers that these yeasts are fundamental for spontaneous fermentations, especially in winemaking where they are thought to be integral to determining the authenticity of natural wines by adding mouthfeel and improved flavor integration [2]. In addition, non-Saccharomyces yeasts have been utilized to obtain alcoholic beverage with lower ethanol yields to match the consumer trends of low alcohol drinks [3-10].

Out of the non-Saccharomyces yeasts, Torulaspora delbrueckii is considered the most common, commercially available yeast species. It is the most similar to $S$. cerevisiae in features required for alcoholic fermentation, making it an ideal candidate to be employed for production of a variety of beverages such as: wine, beer, mead, mescal, tequila, cider, etc. [11-16]. Thus far, T. delbrueckii has been utilized to ferment products made from uncommon fruits such as lychee, strawberry tree fruits, raspberries, etc. [17-20]. Depending on the strain, T. delbrueckii can ferment up to an ethanol concentration of $10 \%(\mathrm{v} / \mathrm{v})$ while providing pleasant aromatic properties (fruity esters, lactones, thiols, and terpenes) as well as decreasing undesired compounds (higher alcohols) [20]. For beer, T. delbrueckii increases isoamyl alcohol and ethyl butanoate, as well as produced terpenes are absent in wort such as beta-caryophyllene and geranyl acetone $[14,21]$. For mead production, T. delbrueckii has been proposed to be suitable for producing a sweet type of multifloral honey mead with low ethanol and high residual sugar content [13].

Much more is known about the use of T. delbrueckii in winemaking and the effect it has on final wine products. Their benefits have been suggested to solve current oenological challenges, where pure cultures of $T$. delbrueckii have been shown to produce lower levels of volatile acidity in high-sugar fermentations and less undesirable compounds like hydrogen sulfide and volatile phenols with respect to $S$. cerevisiae $[22,23]$. They also contribute to mouthfeel, by producing more glycerol, polysaccharide, and mannoproteins and less toxic medium-chain fatty acids, resulting in a fuller and higher pallet weight $[2$, 24]. The use of $T$. delbrueckii has also been proposed to mitigate near future winemaking risks due to climate change. They contribute to the development of natural, climate-smart wine systems that aim to prepare for problems such as increased proliferation of unwanted microorganisms and unintentional imbalance of sensory properties, and excess sugar in grapes and therefore elevated ethanol content $[25,26]$. In this study, we focus on a strain of T. delbrueckii isolated from Montilla-Moriles in southern Spain because of its unique ability to ferment high concentrations of sugar and its significance and importance to this region.

While many reports have been made on the benefits of the use of $T$. delbrueckii for wine and beer, production of these results differs based on a variety of uncontrolled environmental factors such as the composition of the starting must or wort [20]. This can be distracting for producers looking to use T. delbrueckii to ferment their own fruits or vegetables different from traditional grapes or grains. In addition, there exists the possibility that $T$. delbrueckii may produce other metabolites in lower concentrations that have not yet been detected, but are able to influence positively or negatively the overall flavor and aroma of alcoholic beverages. Oftentimes, individual compounds that are linked to producing the aroma and flavor or off-flavor exist in concentrations ranging from ng/L (ppt) to $\mathrm{mg} / \mathrm{L}$ (ppm) [27]. Analysis methods such as stir bar sorptive extraction (SBSE) coupled with gas chromatography/mass spectrometry (GC/MS) allows for a higher sensitive and improved compound identity system than conventional methodologies [28-30]. To focus on those compounds metabolized by $T$. delbrueckii that could influence sensory properties, we have focused on the volatile compounds secreted by $T$. delbrueckii and compare them with Saccharomyces cerevisiae under a controlled setting in synthetic, high glucose media using GC-FID and SBSE with GC-MS. The aim is to identify these compounds and uncover the potential of $T$. delbrueckii without the influence of uncontrolled environmental factors, so that the use of this species in modern production of alcoholic beverages can be improved. This unbiased data will be informative to producers of alcoholic beverages, including winemakers and brewers, so that they are able to make informative decisions on the use of T. delbrueckii to fulfill their individual fermentation conditions and improve their product quality.

\section{Materials and methods}

\section{Microorganisms and experimental conditions}

Two yeasts were used for this study: $S$. cerevisiae (ATTCMYA-2451) as the control and T. delbrueckii (ATTCMYA-426) as the experimental strain. Both originate from the Montilla-Moriles region in Spain and are from the yeast collection in the Department of Agricultural Chemistry, Edaphology and Microbiology at the University of Cordoba, 
Spain. The strain of T. delbrueckii was selected for its unique ability to ferment high concentrations of sugar and its significance and importance to this region. The yeasts were separately pre-inoculated in YPD liquid (1\% yeast extract, $2 \%$ peptone, and $2 \%$ glucose) for $24 \mathrm{~h}$. Next, $1 \times 10^{6}$ cells/ $\mathrm{mL}$ were inoculated in $250 \mathrm{~mL}$ flasks with $150 \mathrm{~mL}$ of sterile synthetic fermentation media supplemented with tartaric acid until pH was 3.1 (250 g/L glucose, $0.67 \%$ YNB without amino acids, titratable acidity $0.99 \mathrm{~g} / \mathrm{L}$, expressed as tartaric acid content and YAN $0.106 \mathrm{~g} / \mathrm{L}$ ). The high glucose media were chosen to mimic the high-sugar content of raw materials, such as grape must grow in warm grape growing regions of Southern Europe and the media volume to headspace ratio has been seen to induce desirable fermentation without oxidation, because oxygen is depleted by yeasts in the first $12 \mathrm{~h}$ of fermentation [31]. The flasks were closed with hydrophobic cotton and incubated at $28{ }^{\circ} \mathrm{C}$ with mild agitation $(\sim 100 \mathrm{rpm})$ to ensure homogenization of solutes for 10 days when the non-Saccharomyces are more metabolically active [32]. Each condition was performed in triplicate.

\section{Growth rate and fermentation rate}

Yeast cell growth was monitored every $2 \mathrm{~h}$ until the stationary phase was achieved by measuring growth at OD580 using the Beckman CoulterTM DU 640 Spectrophotometer. Yeast cells range from 5 to $10 \mu \mathrm{m}$ in size [20,33]. Fermentation was tracked by monitoring the $\mathrm{CO}_{2}$ release as a measure of weight loss until constant [34].

\section{Metabolome analysis}

At the beginning (day 0) and end (day 10) period from the growth medium of yeast metabolism during fermentation, $35 \mathrm{~mL}$ of sample was taken and yeast cells were removed by centrifugation at $5000 \mathrm{rpm}, 22{ }^{\circ} \mathrm{C}$ for $10 \mathrm{~min}$ (Thermo Scientific TX-400 Rotor). The supernatant was then analyzed for metabolites. Fermentable sugars, titratable acidity, volatile acidity, $\mathrm{pH}$, and ethanol were also measured by the methods of the International Organisation of Vine and Wine [35]. Fixed acidity was calculated by equivalents of tartaric acid expressed in Table 1. Metabolites related to the sensory properties of wine and fermented beverages, such as major volatiles and polyols, were identified and quantified by gas chromatography (GC) (model 6890 gas chromatograph from Agilent, Palo Alto, CA, USA) with a CP-WAX 57-CB capillary column $(60 \mathrm{~m}$ long $\times 0.25 \mathrm{~mm}$ i.d., $0.4 \mu \mathrm{m}$ film thickness) and a flame ionization detector (FID). Each injection contained $0.5 \mu \mathrm{L}$ aliquots of liquid sample. Further details of the metabolite procedure are outlined in [36].

Volatile compounds in a concentration of less than $10 \mathrm{mg} / \mathrm{L}$ (ppm) were analyzed using SBSE-TD-GC-MS (Stir Bar Sorptive Extraction-Thermal Desorption-Gas
Chromatography-Mass Spectrometry). The GC-7890A chromatograph with MSD 5975 detector from Agilent Technologies (Wilmington, DE, USA) and a Multi- PurposeSampler from Gerstel (Mülheim an der Rühr, Germany) all utilized the software of Chemstation (Agilent Technologies) and Maestro (Gerstel). The compounds were extracted by SBSE with a Twister coated with $10 \mathrm{~mm}$ long, $0.5 \mathrm{~mm}$-thick film of polydimethylsiloxane (PDMS). Next, method outlined in (Tredoux et al., 2008), $10 \mathrm{~mL}$ vial was filled with $5 \mathrm{~mL}$ of sample and $0.1 \mathrm{~mL}$ of internal standard solution $(0.4464 \mathrm{mg} / \mathrm{L}$ ethyl nonanoate in pure ethanol) plus $12 \%$ (v/v) ethanol adjusted to $\mathrm{pH} 3.5,2.6 \mathrm{~g} / \mathrm{L}$ tartaric acid, and $2.2 \mathrm{~g} / \mathrm{L}$ potassium bitartrate to a final volume of $10 \mathrm{~mL}$. The Twister was put into this vial and stirred at $1200 \mathrm{rpm}$ at $20{ }^{\circ} \mathrm{C}$ for $100 \mathrm{~min}$ on a Variomag Multipoint $15 \mathrm{mag}$ netic stirrer from Thermo Fisher Scientific, Inc. (Waltham, MA, USA). After the cycle was complete, the Twister was removed, rinsed, and dried, and then placed in a Thermal Desorption Unit in a desorption tube from Gerstel. Compounds were thermally desorbed at an initial temperature of $35^{\circ} \mathrm{C}$ for $0.1 \mathrm{~s}$ and increased to $280{ }^{\circ} \mathrm{C}$ at $120{ }^{\circ} \mathrm{C} / \mathrm{min}$ for $10 \mathrm{~min}$ followed by a helium stream at $16 \mathrm{~mL} / \mathrm{min}$ in splitless mode into a Cooled Injection System (CIS-4) from Agilent Technologies furnished with an inlet liner packed with Tenax ${ }^{\circledR}(3 \times 2 \mathrm{~mm})$. The CIS-4 had the following program: $25^{\circ} \mathrm{C}$ (hold $0.05 \mathrm{~s}$ ), $12{ }^{\circ} \mathrm{C} / \mathrm{s}$ ramp to $280{ }^{\circ} \mathrm{C}(7 \mathrm{~min}) ; 16 \mathrm{~mL} /$ min helium inlet flow. The $7890 \mathrm{GC}$ instrument was set with an HP-5MS-fused silica capillary column $(30 \mathrm{~m} \times 0.25 \mathrm{~mm}$ i.d., $0.25 \mu \mathrm{m}$ film) from Agilent Technologies (Wilmington, DE, USA). Initial oven temperature was set to $50^{\circ} \mathrm{C}(2 \mathrm{~min})$ and then raised $4{ }^{\circ} \mathrm{C} / \mathrm{min}$ to $190{ }^{\circ} \mathrm{C}(10 \mathrm{~min})$. The MSD was set at $70 \mathrm{eV}$ in the electron impact mode (EI), with the mass range at $35-550 \mathrm{Da}$ at $150^{\circ} \mathrm{C}$. All samples were measured in triplicate. Identification of compounds was conducted by comparing peaks of aroma compounds with mass spectra in the NIST08 and Wiley7 libraries. Linear retention indices (LRI) for standards compiled in the NIST Web Book of Chemistry (2014) were used to confirm the compounds. Next, quantification was accomplished based on response factors, where the standard solutions of each compound with known concentration were subjected to the same procedures as the samples and using the target and qualifier ions from their respective mass spectra from the Chemstation.

\section{Statistical analysis}

Statistical analysis was performed using the software package Statgraphics ${ }^{\circledR}$ Centurion XVI from Stat Points Technologies, Inc. (Warrenton, Virginia, USA) for the following methods: ANOVA (Analysis Of Variance) and Fisher test for the establishment of Homogeneous Groups (HG) at a significance level $p \leq 0.05$ and Principal Component Analysis 


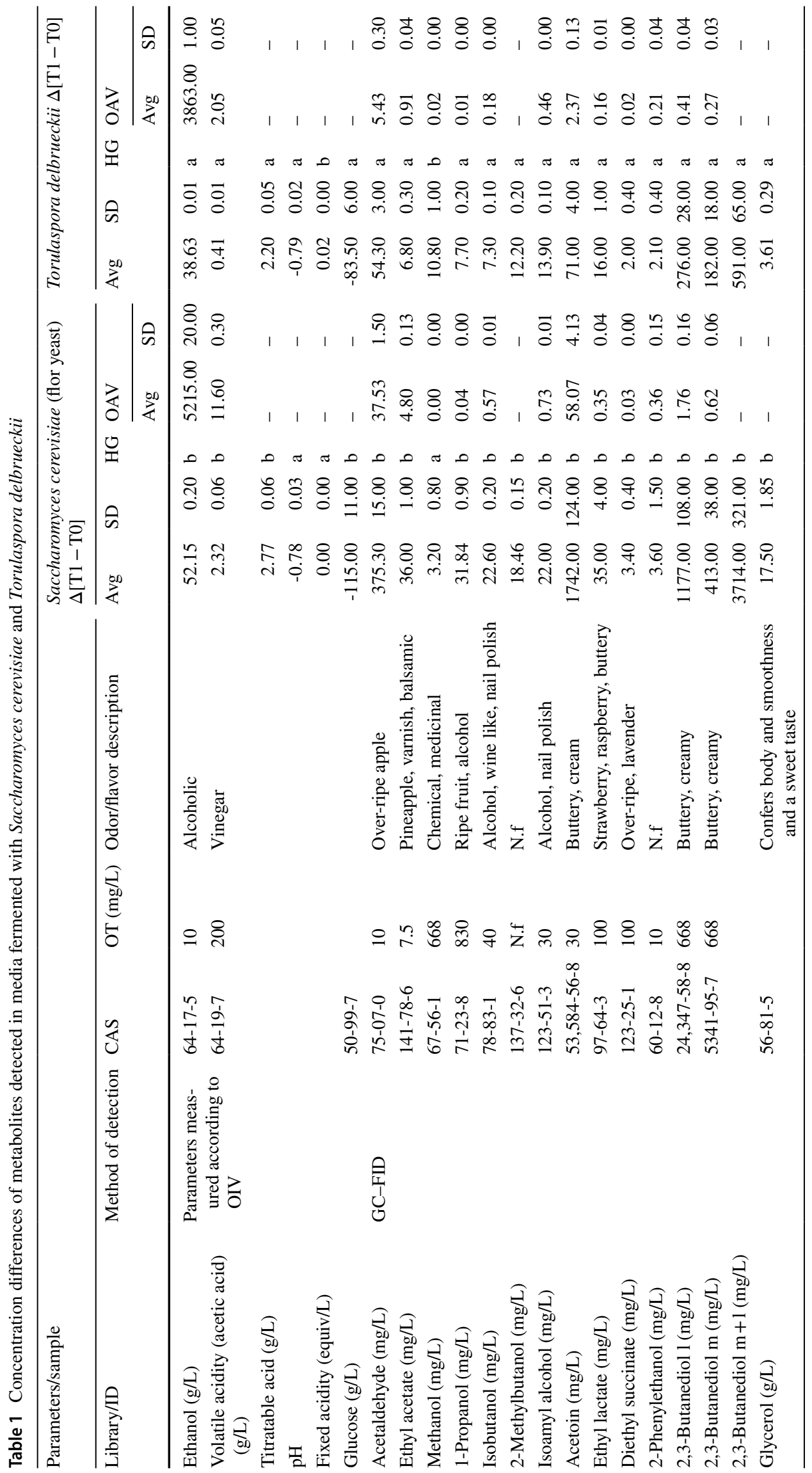




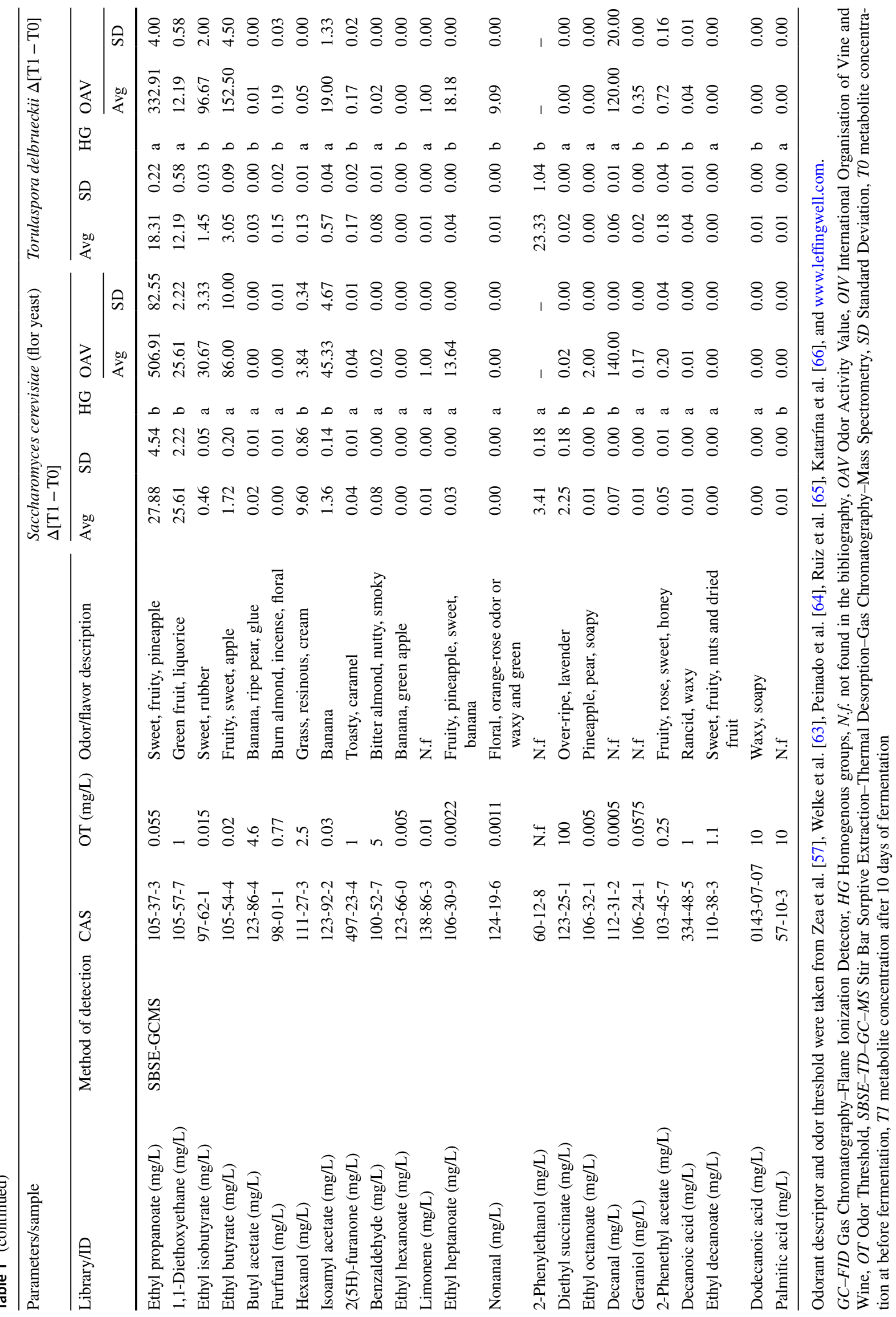




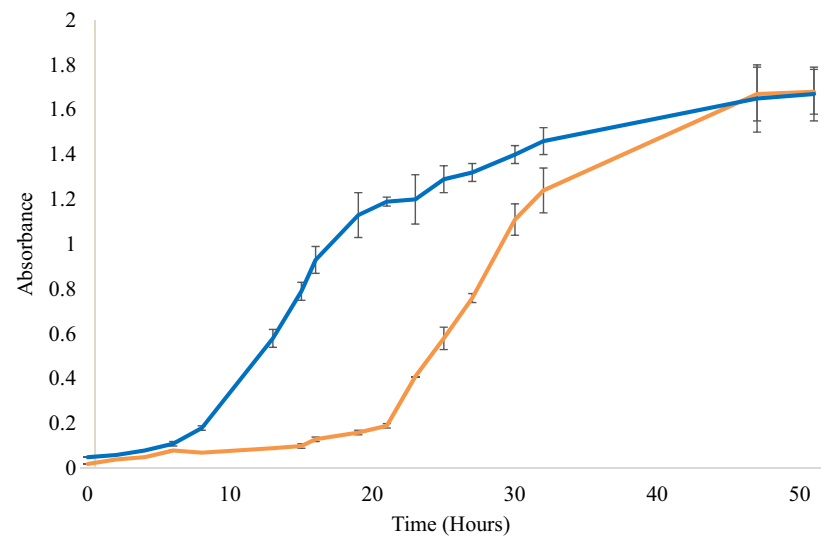

Fig. 1 Growth rate of Saccharomyces cerevisiae (blue) and Torulaspora delbrueckii (orange)

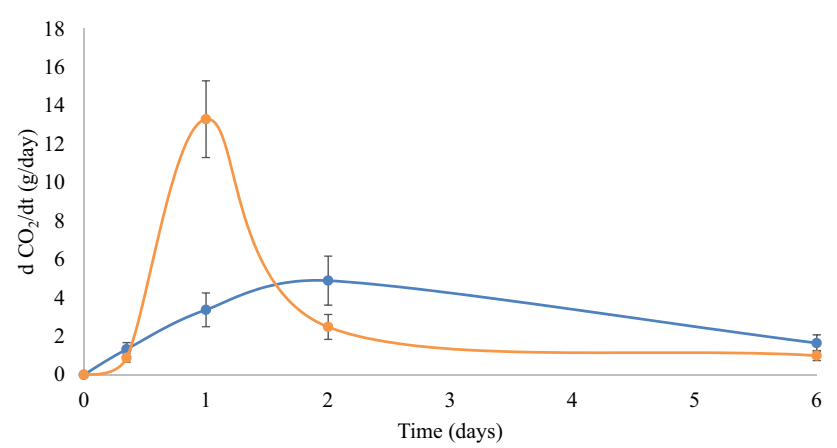

Fig. 2 Fermentation kinetics of Saccharomyces cerevisiae (blue) and Torulaspora delbrueckii (orange)

(PCA). Sunray plots were made by Statgraphics ${ }^{\circledR}$ Centurion XVI, while PCAs were made using the software PAST [37].

\section{Results and discussion}

The growth pattern of $T$. delbrueckii exhibited an initial start later than $S$. cerevisiae, where the former culture had a lag phase of $21 \mathrm{~h}$ and the latter culture of only $8 \mathrm{~h}$ (Fig. 1). Once the exponential phase was reached, the growth rate appeared to be similar, and both reached the same final cell concentration of around $48 \mathrm{~h}$. Interestingly, fermentation kinetics displayed different patterns between the two yeasts where $T$. delbrueckii fermented at a much more rapid rate than $S$. cerevisiae, reaching a peak of over $13 \mathrm{~g} /$ day in little over $24 \mathrm{~h}$ (Fig. 2). After 1.5 days, there appeared to be no more $\mathrm{CO}_{2}$ significant release with $T$. delbrueckii. S. cerevisiae peaked later at around day 2, but the $\mathrm{CO}_{2}$ release was less than two-thirds ( $4 \mathrm{~g} /$ day) of T. delbrueckii. Fermentation rate continued at a gradual pace until the end of day 6. T. delbrueckii has been reported to have higher specific rates of $\mathrm{CO}_{2}$ release and $\mathrm{O}_{2}$ consumption than $S$. cerevisiae [20, 36], matching results of this study.

When observing total glucose consumption and product yield, $T$. delbrueckii consumed less glucose $(84 \mathrm{~g} / \mathrm{L})$ than S. cerevisiae $(137 \mathrm{~g} / \mathrm{L})$ and produced less ethanol $39 \mathrm{~g} / \mathrm{L}$ vs $52 \mathrm{~g} / \mathrm{L}$, respectively (Fig. 3). Glucose consumption is within the range reported in the previous literature [13, 38]. However, if the product yield was expressed as a percentage $(\mathrm{m} / \mathrm{m})$, T. delbrueckii converted $46 \%$ of the consumed glucose to ethanol, whereas S. cerevisiae converted $45 \%$ of the glucose. While both yeasts have similar glucose to ethanol metabolizing efficiency, S. cerevisiae may be able to produce more ethanol, because it is able to switch to respiro-fermentative metabolism faster than T. delbrueckii during decreasing the oxygen feed rate conditions [39]. T. delbrueckii is also known to be sensitive to a low oxygen content, and perhaps, this stress could impact the rate of glucose uptake unlike $S$. cerevisiae $[40,41]$.

\section{Metabolism differences between T. delbrueckii and S. cerevisiae}

Within the parameters measured according to OIV (2012), five out of the six were significantly different $(p$ value $\leq 0.05$ ) between the two yeasts, except for the $\mathrm{pH}$. Significant $\mathrm{pH}$ drops were also observed in the previous studies using these strains [13, 42, 43]. In $S$. cerevisiae, more glucose was consumed and more ethanol produced compared to $T$. delbrueckii (Fig. 3). These match with the previous reports, where T. delbrueckii consistently produced lower ethanol concentration compared to traditional fermentations [44]. Likewise, volatile acidity was significantly lower in $T$. delbrueckii, $1 / 5$ of the amount produced by $S$. cerevisiae, which also lines up with the previous reports $[8,34,45]$. T. delbrueckii has the tendency to not produce excessive acetic acid in response to hyper-osmotic conditions, unlike S. cerevisiae. This feature is especially attractive in winemaking, because the volatile acidity concentration is often typically tied to the measure of wine quality, where concentrations above $0.8 \mathrm{~g} / \mathrm{L}$ are considered higher than normal and can lead to a vinegar-like odor [2].

Fourteen major volatile compounds were identified and quantified by GC-FID: acetaldehyde, ethyl acetate, methanol, 1-propanol, isobutanol, 2-methylbutanol, isoamyl alcohol, acetoin, ethyl lactate, diethyl succinate, 2-phenylethanol, 2,3-butanediol 1+ m, and glycerol. All metabolites presented significant changes ( $p$ value $\leq 0.05$ ) between strains and were produced in higher quantities by $S$. cerevisiae than $T$. delbrueckii except for methanol (Table 1) and match with those of previous studies [46]. The sunray plot (Fig. 4B) visually represents unique differences in the volatile footprint where the end of the ray is the mean value plus three standard deviations and the origin is the mean 


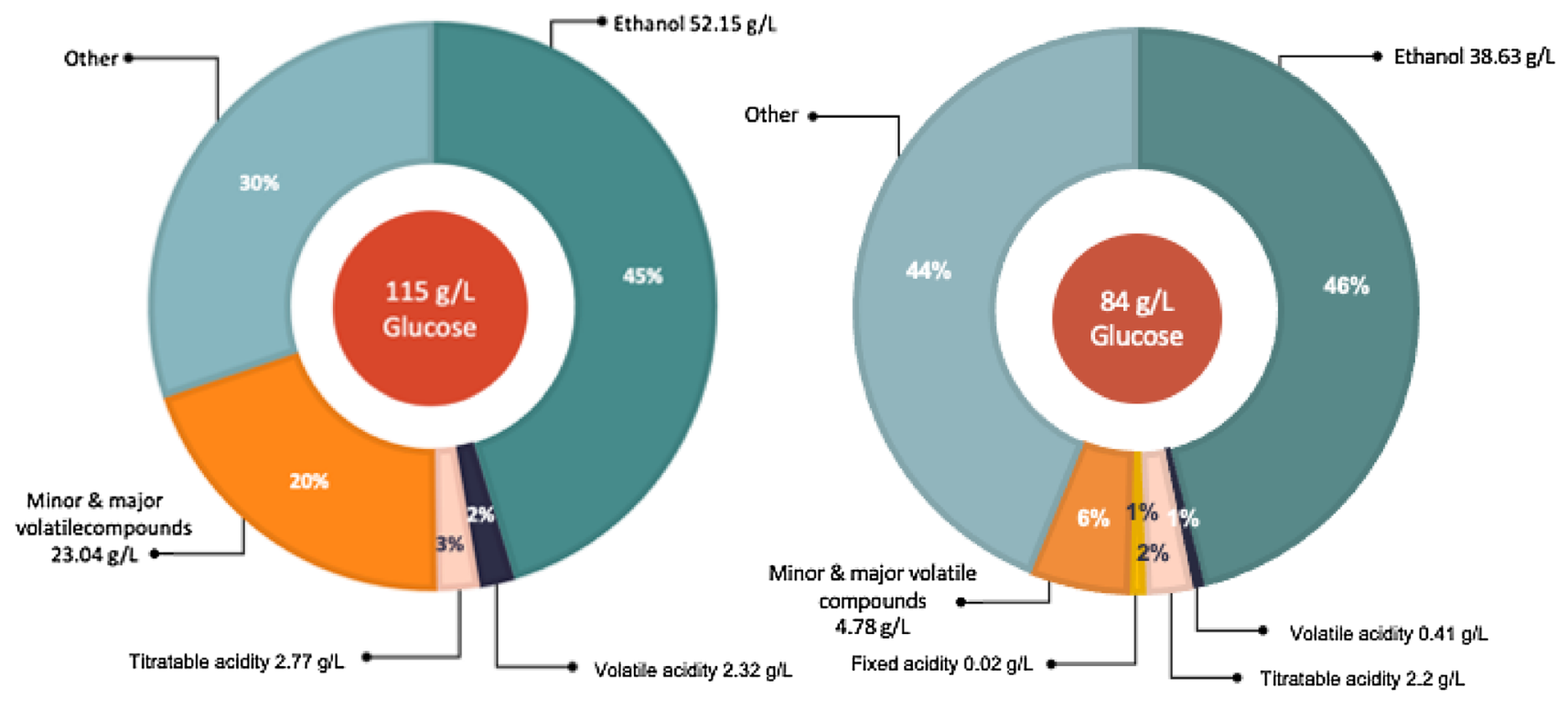

Saccharomyces cerevisiae

Torulaspora delbrueckii

Fig. 3 Glucose consumed by yeasts Saccharomyces cerevisiae and Torulaspora delbrueckii (center circle) and percentage of glucose metabolized into the measured parameters (outer circle)

A

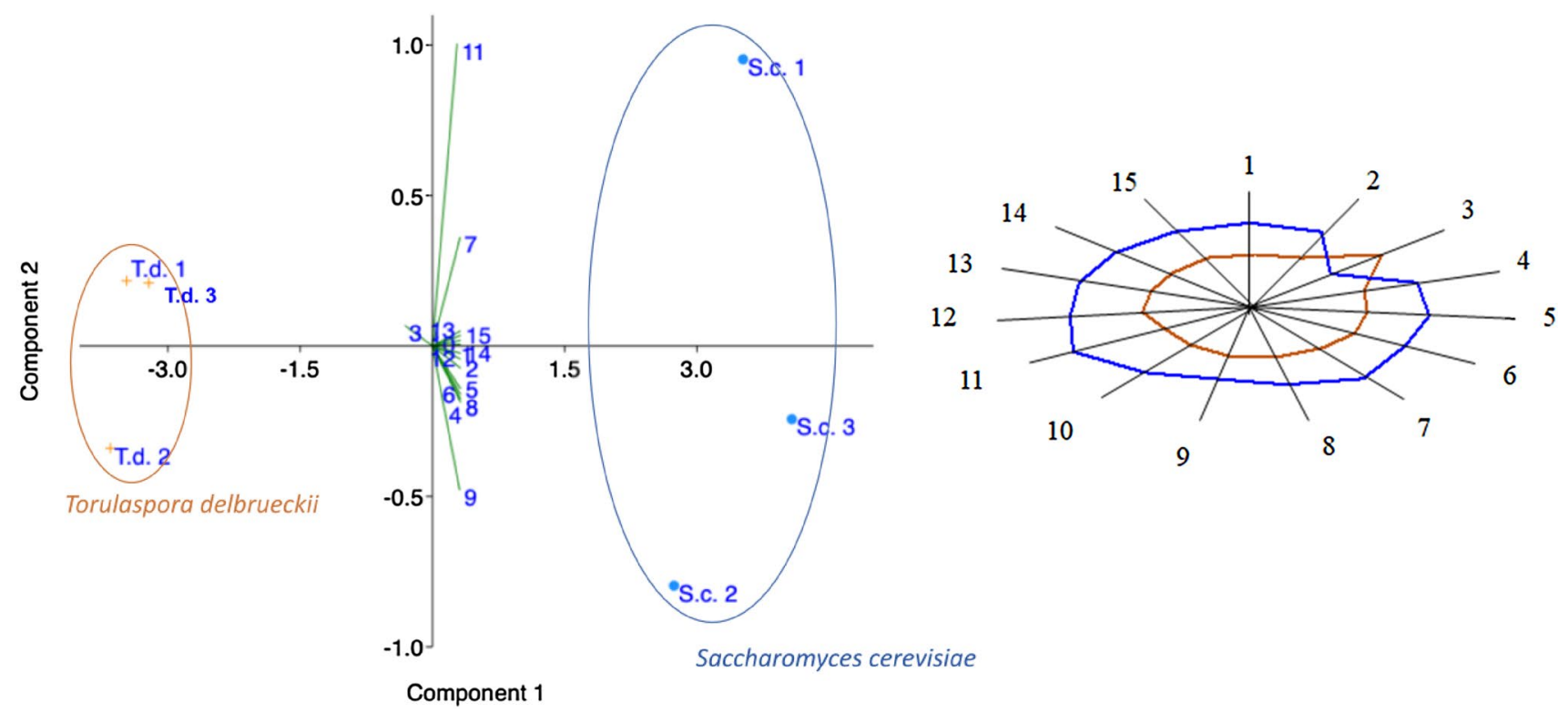

Fig. 4 Principal component analysis (A) and Sunray Plots (B) of compounds quantified by the GC-FID from the metabolism of Saccharomyces cerevisiae (blue) and Torulaspora delbrueckii (orange). 1: acetaldehyde; 2: ethyl acetate; 3: methanol; 4: 1-propanol; 5: isob- utanol; 6: 2-methylbutanol; 7: isoamyl alcohol; 8: acetoin; 9: ethyl lactate; 10: diethyl succinate; 11: 2-phenylethanol; 12: 2,3-butanediol 1; 13: 2,3-butanediol m; 14: 2,3-butanediol 1+m; 15: glycerol

$2.26 \%$ ), also reflects a similar pattern, where methanol is the only variable on the left side of the y-axis, closest to the T. delbrueckii cluster, while all other variables project over brueckii is distinctly different from $S$. cerevisiae, because the methanol sharply juts out. The PCA (PC1 96.50\% and PC2 
the right side of the y-axis toward S. cerevisiae (Fig. 4A). Methanol is an alcohol that is scarcely produced by yeasts [13]. Synthesis occurs during the reversible demethylation of methyl esters by a carboxyl methyl esterase [47, 48]. The odor of methanol is pungent and is described to be alcoholic odor when pure [49]. However in this study, the concentration of methanol produced by T. delbrueckii was well below its detection threshold of $668 \mathrm{mg} / \mathrm{L}$, at $10 \mathrm{mg} / \mathrm{L}$.

Twenty-four total minor volatile metabolites were identified, and out of these, 20 were significantly different ( $p$ value $\leq 0.05$ ) (Table 1). The metabolites are represented on a PCA (PC1 $83.41 \%$ and PC2 10.03\%), where decanal, palmitic acid, diethyl succinate, ethyl octanoate, 1,1-diethoxyethane, ethyl propanoate, hexanol, and isoamyl acetate project over the left side of the $y$-axis, closest to the cluster of S. cerevisiae. Ethyl isobutyrate, ethyl butyrate, butyl acetate, furfural, $2(5 \mathrm{H})$-furanone, benzaldehyde, ethyl hexanoate, limonene, ethyl heptanoate, nonanal, 2-phenylethanol, geraniol, 2-phenethyl acetate, decanoic acid, ethyl decanoate, and dodecanoic acid projected on the right side of the y-axis, closest to the cluster of T. delbrueckii (Fig. 5A). These same metabolites that projected toward the right side of the $y$-axis in the PCA were also distinctive in determining the profile of T. delbrueckii in the sunray plot (Fig. 5B). Those compounds that had the most impact on aroma profile are discussed in greater depth in the following section.

\section{Compounds affecting aroma}

Assessment of the potential impact of these volatile compounds on aroma can be determined by the Odor Activity
Value (OAV). The OAV is calculated as the concentration: odor threshold ratio, which allows an objective comparison of volatile compounds that could influence the aroma of beverages. Figure 6 shows the OAV changes of metabolites produced by $T$. delbrueckii and $S$. cerevisiae, where the larger the OAV, the greater the impact of aroma of that compound. The compounds produced by $T$. delbrueckii that were the greatest contributors to aroma are ethanol $(\mathrm{OAV}=3863.00)$, ethyl propanoate $(332.91)$, ethyl butyrate (152.50), decanal (120.00), ethyl isobutyrate (96.67), isoamyl acetate (19.00), ethyl heptanoate (18.18), 1,1-diethoxyethane (12.19) and nonanal (9.09), acetaldehyde (5.00), ethyl acetate (1.33), acetoin (2.33), and limonene (1.00).

Out of these compounds, T. delbrueckii presents a greater change in OAV compared to $S$. cerevisiae for ethyl isobutyrate, ethyl butyrate, ethyl heptanoate, and nonanal. Each metabolite is associated with an aroma descriptor which could contribute to providing a unique character to the medium. Ethyl isobutyrate is reminiscent of a sweet and rubber smell. Ethyl butyrate is characterized to have fruity, sweet, and apple like aromas and pineapple tastes [50]. Ethyl heptanoate is described to contribute aromas that are fruity, pineapple, sweet, and banana. Nonanal is associated with floral, orange-rose odor or waxy and green [51]. Overall, the compounds with higher OAV in T. delbrueckii are sweet or fruity, which suggests that the final product when fermented with $T$. delbrueckii will most likely reflect these aromas.
A

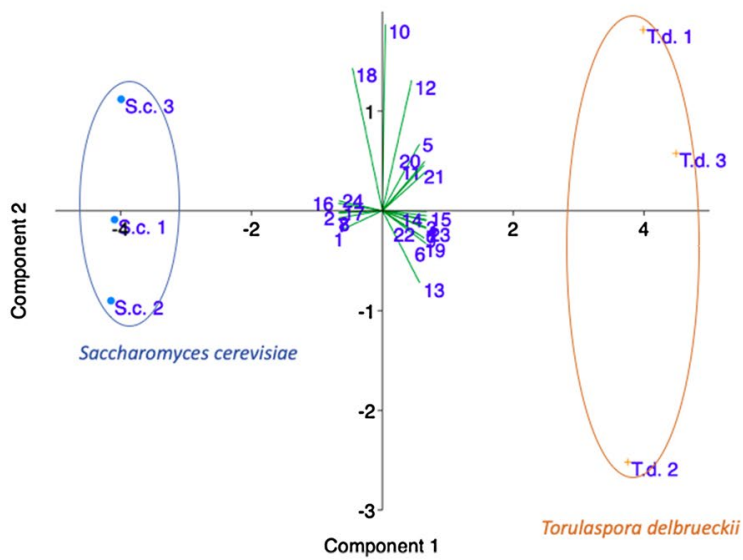

B

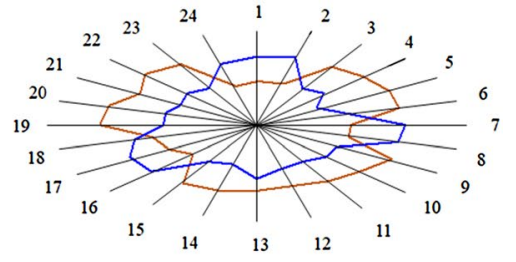

isoamyl acetate; 9: 2(5H)-furanone; 10: benzaldehyde; 11: ethyl hexanoate; 12: limonene; 13: ethyl heptanoate; 14: nonanal; 15: 2-phenylethanol; 16: diethyl succinate; 17: ethyl octanoate; 18: decanal; 19: geraniol; 20: 2-phenethyl acetate; 21: decanoic acid; 22: ethyl decanoate; 23: dodecanoic acid; 24: palmitic acid 


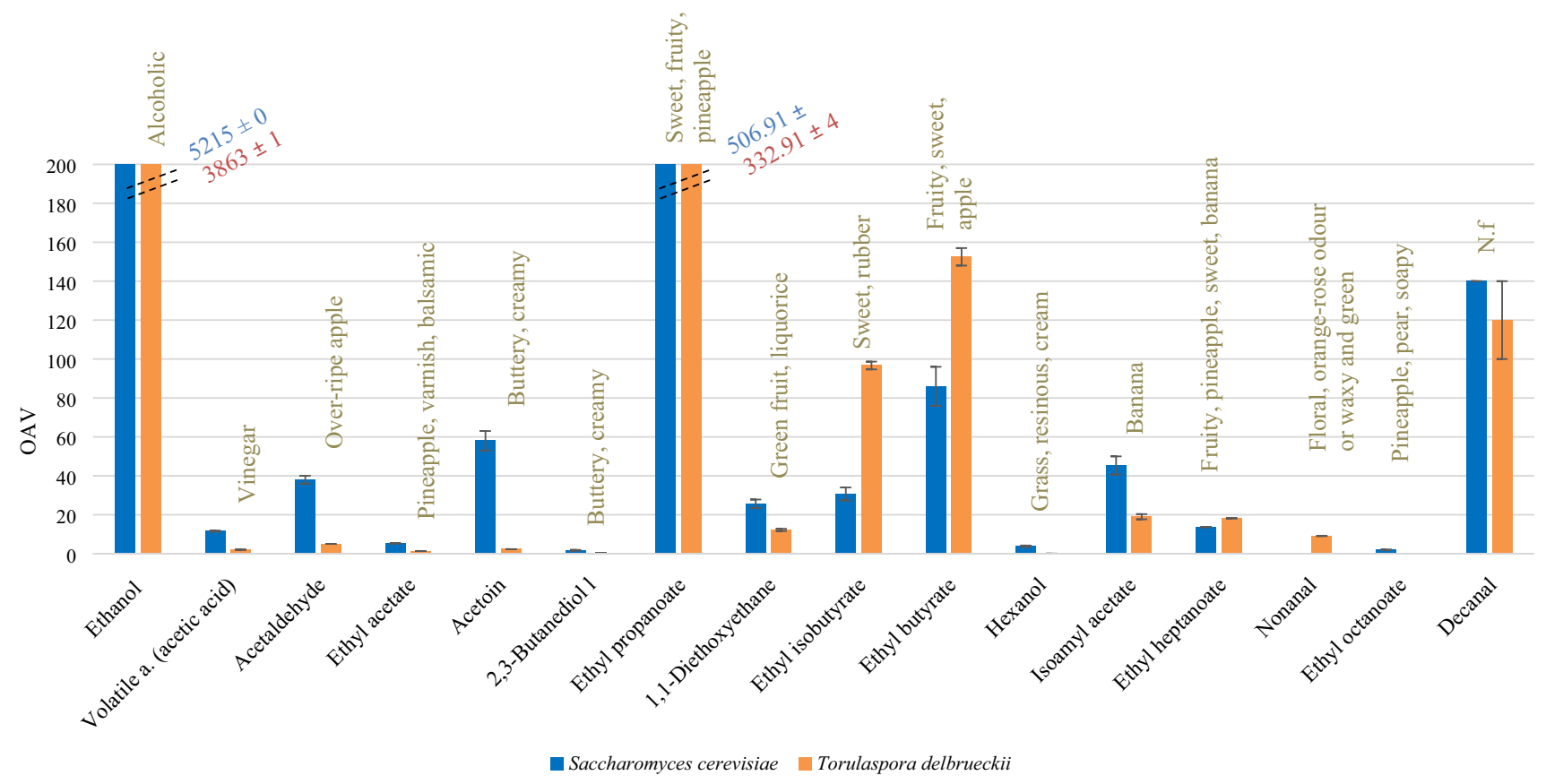

Fig. 6 Odor activity values (OAV) of compounds anabolized by Saccharomyces cerevisiae (blue) and Torulaspora delbrueckii (orange)

\section{Compounds identified for the first time in $T$. delbrueckii}

While all compounds mentioned in this study have been reported in S. cerevisiae, this study has reported metabolites, identified as far as our knowledge, for the first time by T. delbrueckii. These metabolites are: 1,1-diethoxyethane, $2(5 \mathrm{H})$-furanone, limonene, ethyl heptanoate, dodecanoic acid, and palmitic acid. The metabolite found in the highest concentration in this group from this study was 1,1-diethoxyethane at $12.19 \mathrm{mg} / \mathrm{L}$ with a significant OAV change that would impact aroma. This metabolite is known to be a key factor in giving sherry wine and its unique characteristic aroma [52-56]. Standing alone, 1,1-diethoxyethane has an active odorant profile of green fruit and liquorice, as well as balsamic notes [54, 56]. Zea, Serratosa, Mérida, and Moyano [57] claimed that acetals combined with other alcohols produce strong woody notes; however, Etiévant [58] described 1,1-diethoxyethane as the only acetal that can contribute to wine aroma.

Most of the other compounds that were identified in T. delbrueckii were not present in high amounts to evoke strong impacts on the sensory property; however, many have added benefits apart from an aroma profile. For example, dodecanoic acid and palmitic acid are fatty acids that have antimicrobial properties. Especially, dodecanoic acid, or lauric acid, can be converted to monolaurin, which is able to destroy the lipid membrane of bacteria, making it a natural food preservative [59]. Another metabolite is
$2(5 \mathrm{H})$-furanone, which belongs to the furanone subclass of organic compounds and has an easily oxidized nature that allows them to be important signaling molecules. The furanones have an important role as a pharmaceutical for their anti-carcinogenic activity as well as their antioxidant quality that is comparable to ascorbic acid [60]. Furanones are produced by yeasts are thought to be an indirect metabolite through a spontaneous reaction between acetaldehyde and $\alpha$-ketobutyrate [61]. In wines, they contribute to a "nutty" aroma first discovered in sweet botrytized wines [62].

\section{Conclusion}

Overall, this study presents a general, untargeted volatilome profile of $T$. delbrueckii from the Montilla-Moriles region of Spain when subjected to a high glucose fermentation medium. We can detect low concentration, but aromatically impactful metabolites that otherwise may have gone unnoticed in complex, natural media. We were also able to find new metabolites of $T$. delbrueckii which were 1,1-diethoxyethane, $2(5 \mathrm{H})$-furanone, limonene, ethyl heptanoate, 2-phenethyl acetate, dodecanoic acid, and palmitic acid. While the concentrations of these newly detected metabolites in T. delbrueckii were small, it is important to note here that environmental and conditional differences and parameters like: nitrogen sources use, grape variety, and oxygen addition can influence yeast activity. However, these preliminary data can be valuable in designing the next steps in 
enhancing the metabolite production of this lesser-known yeast. From here, wine producers, brewers, and fermented beverage producers can regulate fermentation conditions to adjust the production of desired metabolites to their needs.

In today's growing market for alcoholic beverages, consumer demand is shifting toward new, unique aroma/taste. Application of $T$. delbrueckii will likely expand and grow as this trend evolves in the near future. With this in mind, the data in this study are widely applicable to benefit those producers looking to make new products as well as improving existing ones by fermentation with the less traditional, but an up-and-coming yeast-T. delbrueckii.

Funding Open Access funding provided thanks to the CRUE-CSIC agreement with Springer Nature. This study was supported by the XXIII Programa Propio de Fomento de la Investigación 2018 (MOD. 4.2. SINERGIAS, Ref. XXIII PP Mod. 4.2) from the University of Cordoba (Spain).

Availability of data and materials Not applicable.

Code availability Not applicable.

\section{Declarations}

Conflict of interest The authors declare no conflict of interest.

Ethics approval Not applicable.

Consent to participate Not applicable.

Consent for publication Not applicable.

Open Access This article is licensed under a Creative Commons Attribution 4.0 International License, which permits use, sharing, adaptation, distribution and reproduction in any medium or format, as long as you give appropriate credit to the original author(s) and the source, provide a link to the Creative Commons licence, and indicate if changes were made. The images or other third party material in this article are included in the article's Creative Commons licence, unless indicated otherwise in a credit line to the material. If material is not included in the article's Creative Commons licence and your intended use is not permitted by statutory regulation or exceeds the permitted use, you will need to obtain permission directly from the copyright holder. To view a copy of this licence, visit http://creativecommons.org/licenses/by/4.0/.

\section{References}

1. Jolly NP, Varela C, Pretorius IS (2014) Not your ordinary yeast: non-Saccharomyces yeasts in wine production uncovered. FEMS Yeast Res. https://doi.org/10.1111/1567-1364.12111

2. Benito S (2018) The impact of Torulaspora delbrueckii yeast in winemaking. Appl microbiol biotec. Springer, Verlag, Berlin. https://doi.org/10.1007/s00253-018-8849-0

3. Ciani M, Beco L, Comitini F (2006) Fermentation behavior and metabolic interactions of multistarter wine yeast fermentations.
Int J Food Microbiol. https://doi.org/10.1016/j.ijfoodmicro.2005. 11.012

4. Comitini F, Gobbi M, Domizio P, Romani C, Lencioni L, Mannazzu I, Ciani M (2011) Selected non-Saccharomyces wine yeasts in controlled multistarter fermentations with Saccharomyces cerevisiae. Food Microbiol. https://doi.org/10.1016/j.fm.2010.12.001

5. Di Maio S, Genna G, Gandolfo V, Amore G, Ciaccio M, Oliva D (2012) Presence of Candida zemplinina in sicilian musts and selection of a strain for wine mixed fermentations. S Afr J Enol Viticul. https://doi.org/10.21548/33-1-1309

6. Ferraro L, Fatichenti F, Ciani M (2000) Pilot scale vinification process using immobilized Candida stellata cells and Saccharomyces cerevisiae. Process Biochem. https://doi.org/10.1016/ S0032-9592(00)00148-5

7. Magyar I, Tóth T (2011) Comparative evaluation of some oenological properties in wine strains of Candida stellata, Candida zemplinina, Saccharomyces uvarum and Saccharomyces cerevisiae. Food Microbiol. https://doi.org/10.1016/j.fm.2010.08.011

8. Sadoudi M, Tourdot-Maréchal R, Rousseaux S, Steyer D, Gallardo-Chacón JJ, Ballester J, Vichi S, Guérin-Schneider R, Caixach J, Alexandre H (2012) Yeast-yeast interactions revealed by aromatic profile analysis of Sauvignon Blanc wine fermented by single or co-culture of non-Saccharomyces and Saccharomyces yeasts. Food Microbiol. https://doi.org/10.1016/j.fm.2012.06.006

9. Reference: Reference [9] was mentioned in the manuscript; however, this was not included in the reference list. As a rule, all mentioned references should be present in the reference list. Please provide the reference details to be inserted in the reference list and ensure that all references are cited in ascending numerical order

10. Soden A, Francis IL, Oakey H, Henschke PA (2000) Effects of cofermentation with Candida stellata and Saccharomyces cerevisiae on the aroma and composition of Chardonnay wine. Aust J Grape Wine Res. https://doi.org/10.1111/j.1755-0238.2000.tb00158.x

11. Alcazar-Valle M, Gschaedler A, Gutierrez-Pulido H, AranaSanchez A, Arellano-Plaza M (2019) Fermentative capabilities of native yeast strains grown on juices from different Agave species used for tequila ofand mezcal production. Braz J Microbiol. https://doi.org/10.1007/s42770-019-00049-7

12. Morata A, Escott C, Bañuelos MA, Loira I, Del Fresno JM, González C, Suárez-lepe JA (2020) Contribution of non-Saccharomyces yeasts to wine freshness. A review. In Biomol. https:// doi.org/10.3390/biom10010034

13. Sottil C, Salor-Torregrosa JM, Moreno-Garcia J, Peinado J, Mauricio JC, Moreno J, Garcia-Martinez T (2019) Using Torulaspora delbrueckii, Saccharomyces cerevisiae and Saccharomyces bayanus wine yeasts as starter cultures for fermentation and quality improvement of mead. Euro Food Res Tech 245(12):2705-2714. https://doi.org/10.1007/s00217-019-03384-Z

14. Toh DWK, Chua JY, Lu Y, Liu SQ (2020) Evaluation of the potential of commercial non-Saccharomyces yeast strains of Torulaspora delbrueckii and Lachancea thermotolerans in beer fermentation. Int J Food Sci Tech. https://doi.org/10.1111/ijfs.14399

15. Verdugo Valdez A, Segura Garcia L, Kirchmayr M, Ramírez Rodríguez P, González Esquinca A, Coria R, Gschaedler Mathis A (2011) Yeast communities associated with artisanal mezcal fermentations from Agave salmiana. Antonie van Leeuwenhoek, Int J Gener Mol Microbiol. https://doi.org/10.1007/s10482-011-9605-y

16. Wei J, Wang S, Zhang Y, Yuan Y, Yue T (2019) Characterization and screening of non-Saccharomyces yeasts used to produce fragrant cider. LWT. https://doi.org/10.1016/j.1wt.2019.03.028

17. Chen D, Yap ZY, Liu SQ (2015) Evaluation of the performance of Torulaspora delbrueckii, Williopsis saturnus, and Kluyveromyces lactis in lychee wine fermentation. Int J Food Microbiol. https:// doi.org/10.1016/j.ijfoodmicro.2015.04.020

18. Li H, Jiang D, Liu W, Yang Y, Zhang Y, Jin C, Sun S (2020) Comparison of fermentation behaviors and properties of raspberry 
wines by spontaneous and controlled alcoholic fermentations. Food Res Int. https://doi.org/10.1016/j.foodres.2019.108801

19. Santo DE, Galego L, Gonçalves T, Quintas C (2012) Yeast diversity in the Mediterranean strawberry tree (Arbutus unedo L.) fruits' fermentations. Food Res Int. https://doi.org/10.1016/j.foodr es.2012.01.009

20. Ramírez M, Velázquez R (2018) The yeast Torulaspora delbrueckii: an interesting but difficult-to-use tool for winemaking. Fermentation. MDPI AG, Basel. https://doi.org/10.3390/ferme ntation4040094

21. Cubillos FA, Gibson B, Grijalva-Vallejos N, Krogerus K, Nikulin J (2019) Bioprospecting for brewers: exploiting natural diversity for naturally diverse beers. Yeast. John Wiley and Sons Ltd., Hoboken. https://doi.org/10.1002/yea.3380

22. Bely M, Sablayrolles JM, Barre P (1990) Automatic detection of assimilable nitrogen deficiencies during alcoholic fermentation in oenological conditions. J Ferment Bioeng. https://doi.org/10. 1016/0922-338X(90)90057-4

23. Moreno JJ, Millán C, Ortega JM, Medina M (1991) Analytical differentiation of wine fermentations using pure and mixed yeast cultures. J Industrial Microbiol. https://doi.org/10.1007/BF015 75881

24. Belda I, Navascués E, Marquina D, Santos A, Calderon F, Benito S (2015) Dynamic analysis of physiological properties of Torulaspora delbrueckii in wine fermentations and its incidence on wine quality. Appl Microbiol Biotech. https://doi.org/10.1007/ s00253-014-6197-2

25. Berbegal C, Fragasso M, Russo P, Bimbo F, Grieco F, Spano G, Capozzi V (2019) Climate changes and food quality: the potential of microbial activities as mitigating strategies in the wine sector. Ferment. MDPI AG, Basel. https://doi.org/10.3390/fermentati on5040085

26. Simonin S, Alexandre H, Nikolantonaki M, Coelho C, TourdotMaréchal R (2018) Inoculation of Torulaspora delbrueckii as a bio-protection agent in winemaking. Food Res Int. https://doi.org/ 10.1016/j.foodres.2018.02.034

27. Tredoux A, De Villiers A, Májek P, Lynen F, Crouch A, Sandra P (2008) Stir bar sorptive extraction combined with GC-MS analysis and chemometric methods for the classification of South African wines according to the volatile composition. J Agric Food Chem. https://doi.org/10.1021/jf0734673

28. Hayasaka Y, MacNamara K, Baldock GA, Taylor RL, Pollnitz AP (2003) Application of stir bar sorptive extraction for wine analysis. Anal Bioanal Chem. https://doi.org/10.1007/s00216-003-1837-x

29. Vararu F, Moreno-García J, Cotea VV, Moreno J (2015) Grape musts differentiation based on selected aroma compounds using SBSE-GC-MS and statistical analysis. Vitis-J Grapevine Res. https://doi.org/10.5073/vitis.2015.54.97-105

30. Varau F, Moreno-Garcia J, Moreno J, Niculaua M, Nechita B, Zamfir C, Colibaba C, Dumitru G-D, Cotea VV (2015) Minor volatile compounds profiles of 'Aligoté' wines fermented with different yeast strains. Not Sci Biol. https://doi.org/10.15835/nsb.7. 1.9545

31. Moreno-García J, Mauricio JC, Moreno J, García-Martínez T (2017) Differential proteome analysis of a flor yeast strain under biofilm formation. Int J Mol Sci. https://doi.org/10.3390/ijms1 8040720

32. Beckner Whitener ME, Stanstrup J, Panzeri V, Carlin S, Divol B, Du Toit M, Vrhovsek U (2016) Untangling the wine metabolome by combining untargeted SPME-GCxGC-TOF-MS and sensory analysis to profile Sauvignon blanc co-fermented with seven different yeasts. Metabolomics. https://doi.org/10.1007/ s11306-016-0962-4

33. Feldmann H (2010) Yeast mol cell bio. Wiley-Blackwell, New York
34. Bely M, Stoeckle P, Masneuf-Pomarède I, Dubourdieu D (2008) Impact of mixed Torulaspora delbrueckii-Saccharomyces cerevisiae culture on high-sugar fermentation. Int J Food Microbiol. https://doi.org/10.1016/j.ijfoodmicro.2007.12.023

35. OIV (2012) Compendium of international methods of analysis of wines and musts. http://www.oiv.int/en/technical-standards-anddocuments/methods-of-analysis

36. Peinado RA, Moreno JA, Muñoz D, Medina M, Moreno J (2004) Gas chromatographic quantification of major volatile compounds and polyols in wine by direct injection. J Agricul Food Chem. https://doi.org/10.1021/jf049369o

37. Hammer $\varnothing$, Harper DAT, Ryan PD (2001) PAST: paleontological statistics software package for education and data analysis. Palaeontol Electronica 4(1):9

38. Tronchoni J, Gamero A, Arroyo-López FN, Barrio E, Querol A (2009) Differences in the glucose and fructose consumption profiles in diverse Saccharomyces wine species and their hybrids during grape juice fermentation. Int J Food Microbiol. https:// doi.org/10.1016/j.ijfoodmicro.2009.07.004

39. Alves-Araújo C, Pacheco A, Almeida MJ, Spencer-Martins I, Leão C, Sousa MJ (2007) Sugar utilization patterns and respirofermentative metabolism in the baker's yeast Torulaspora delbrueckii. Microbiol. https://doi.org/10.1099/mic.0.2006/ 003475-0

40. Hanl L, Sommer P, Arneborg N (2005) The effect of decreasing oxygen feed rates on growth and metabolism of Torulaspora delbrueckii. Appl Microbiol Biotech. https://doi.org/10.1007/ s00253-004-1695-2

41. Visser W, Scheffers WA, Batenburg-Van der Vegte WH, Van Dijken JP (1990) Oxygen requirements of yeasts. Appl Environ Microbiol. https://doi.org/10.1128/aem.56.12.3785-3792.1990

42. López-Menchero JR, Ogawa M, Mauricio JC, Moreno J, MorenoGarcía J (2021) Effect of calcium alginate coating on the cell retention and fermentation of a fungus-yeast immobilization system. LWT. https://doi.org/10.1016/j.lwt.2021.111250

43. Velázquez R, Zamora E, Álvarez ML, Hernández LM, Ramírez M (2015) Effects of new Torulaspora delbrueckii killer yeasts on the must fermentation kinetics and aroma compounds of white table wine. Front Microbiol. https://doi.org/10.3389/fmicb.2015.01222

44. Contreras A, Hidalgo C, Henschke PA, Chambers PJ, Curtin C, Varela C (2014) Evaluation of non-Saccharomyces yeasts for the reduction of alcohol content in wine. Appl Environ Microbiol. https://doi.org/10.1128/AEM.03780-13

45. Ciani M, Maccarelli F (1997) Oenological properties of non-Saccharomyces yeasts associated with wine-making. W J Microbiol Biotech. https://doi.org/10.1023/A:1008825928354

46. Canonico L, Comitini F, Ciani M (2018) Torulaspora delbrueckii for secondary fermentation in sparkling wine production. Food Microbiol. https://doi.org/10.1016/j.fm.2018.03.009

47. Gagnon C, Harbour D, \& Camato R (1984) Purification and characterization of protein methylesterase from rat kidney. $J$ Biol Chem. 259(16).

48. Kehry MR, Doak TG, Dahlquist FW (1984) Stimulus-induced changes in methylesterase activity during chemotaxis in Escherichia coli. J Biol Chem 259:11828-11835

49. O'Neil MJ (2013) The merck index: an encyclopedia of chemicals, drugs, and biologicals, 15th edition. R Soc Chem. https://doi.org/ 10.1002/ddr.21085

50. Burdock GA (2016) Fenaroli's handbook of flavor ingredients, sixth edition. In: Fenaroli's handbook of flavor ingredients, sixth edition.

51. Lewis RJ (2007) Hawley's condensed chemical dictionary, 15th ed Sr. John Wiley \& Sons, Inc.: Hoboken, New Jersey, CRC Press, Boca Raton, Florida, United States. J Am Chem Soc. https://doi. org/10.1021/ja0769144 
52. Cortes MB, Moreno J, Zea L, Moyano L, Medina M (1998) Changes in aroma compounds of sherry wines during their biological aging carried out by Saccharomyces cerevisiae races bayanus and capensis. J Agric Food Chem. https://doi.org/10.1021/ jf970903k

53. Etievan PX (1981) Volatile phenol determination in wine. J Agric Food Chem. https://doi.org/10.1021/jf00103a017

54. Moreno-García J, Raposo RM, Moreno J (2013) Biological aging status characterization of Sherry type wines using statistical and oenological criteria. Food Res Int. https://doi.org/10.1016/j.foodr es.2013.07.031

55. Muñoz D, Peinado RA, Medina M, Moreno J (2007) Biological aging of sherry wines under periodic and controlled microaerations with Saccharomyces cerevisiae var. capensis: effect on odorant series. Food Chem. https://doi.org/10.1016/j.foodchem.2005. 10.065

56. Peinado RA, Mauricio JC (2009) Biologically aged wines. W Chem Biochem. https://doi.org/10.1007/978-0-387-74118-5_5

57. Zea L, Moyano L, Moreno JA, Medina M (2007) Aroma series as fingerprints for biological ageing in fino sherry-type wines. J Sci Food Agric. https://doi.org/10.1002/jsfa.2992

58. Etiévant P, Schreier P (1995) Bioflavor 95. (INRA) Institut' National de la Recherche Agronomique, Paris, France

59. Srivastava Y, Semwal AD, Sharma GK (2018) Virgin coconut oil as functional oil. Ther Probiotic Unconv Foods. https://doi.org/ 10.1016/b978-0-12-814625-5.00015-7

60. Slaughter JC (1999) The naturally occurring furanones: formation and function from pheromone to food. Biol Rev Cambridge Philos Soc. https://doi.org/10.1017/s0006323199005332

61. Pham TT, Guichard E, Schlich P, Charpentier C (1995) Optimal conditions for the formation of sotolon from $\alpha$-ketobutyric acid in the French "Vin Jaune." J Agricul Food Chem. https://doi.org/ 10.1021/jf00058a012

62. Masuda M, Okawa EI, Nishimura KI, Yunome H (1984) Identification of 4,5-dimethyl-3-hydroxy-2(57/)-furanone (Sotolon) and ethyl 9-hydroxynonanoate in botrytised wine and evaluation of the roles of compounds characteristic of it. Agric Biol Chem. https:// doi.org/10.1271/bbb1961.48.2707

63. Welke JE, Zanus M, Lazzarotto M, Zini CA (2014) Quantitative analysis of headspace volatile compounds using comprehensive two-dimensional gas chromatography and their contribution to the aroma of Chardonnay wine. Food Res Int. https://doi.org/10. 1016/j.foodres.2014.02.002

64. Peinado RA, Moreno J, Bueno JE, Moreno JA, Mauricio JC (2004) Comparative study of aromatic compounds in two young white wines subjected to pre-fermentative cryomaceration. Food Chem.https://doi.org/10.1016/S0308-8146(03)00282-6

65. Ruiz MJ, Moyano L, Zea L (2014) Changes in aroma profile of musts from grapes cv. Pedro Ximenez chamber-dried at controlled conditions destined to the production of sweet Sherry wine. LWT. https://doi.org/10.1016/j.lwt.2014.04.056

66. Katarína F, Katarína M, Katarína Ď, Ivan Š, Fedor M (2014) Influence of yeast strain on aromatic profile of Gewürztraminer wine. LWT. https://doi.org/10.1016/j.lwt.2014.05.057

Publisher's Note Springer Nature remains neutral with regard to jurisdictional claims in published maps and institutional affiliations. 